\title{
O estigma da feminilidade nas organizações: um estudo a partir da visão de sujeitos gays
}

\author{
Renan Gomes de Moura e Rejane Prevot Nascimento
}

\section{RESUMO}

Tratados muitas vezes como minorias ou excluídos, os homossexuais, assim como outras categorias marginalizadas da sociedade, estão submetidos ao controle social por parte de um grande grupo hegemônico, que determina o que é tido como "normal" na sociedade (Pereira, 2009). Neste sentido, este trabalho se propõe compreender a estigmatização da feminilidade nas organizações, pela perspectiva do sujeito gay. Foram entrevistados nove (09) sujeitos gays masculinos assumidos, residentes no estado do Rio de Janeiro, inseridos em diferentes atividades profissionais e com diferentes níveis de formação. O corpus da pesquisa foi analisado por meio da análise de conteúdo. Constatou-se que o estigma da feminilidade pode ser compreendido a partir do momento em que o "ser feminino" é visto como inferior ao homem pela sociedade e pelas organizações, seja por meio das palavras ou por meio de comportamentos, com o objetivo de manter o poder heteromasculino.

Palavras-chave: estigma; feminilidades; gay; organizações.

\section{The stigma of femininity in organizations: a study with gay subjects' perspectives}

\section{ABSTRACT}

Homosexuals are often treated as minorities or excluded, as well as other marginalized categories of society. They are subjected to social control by a large hegemonic group, which determines what is considered "normal" in society (Pereira, 2009). In this sense, this work aims to understand the stigmatization of femininity in organizations, from the perspective of the gay subjects. Nine (9) male gay subjects were interviewed, all from the state of Rio de Janeiro. The interviewed subjects are involved in different professional activities, with different levels of education. The corpus of the research was analyzed through content analysis. It has been found that the stigma of femininity can be understood from the moment that the "feminine being" is seen as inferior to man by society and organizations, through the use of words or means of behavior in order to maintain the masculine heteronormative power.

Keywords: stigma; femininity; gay; organizations.

Recebido em: 27/10/2018 Revisado em: 22/02/2019 Aprovado em: 08/01/2020

Check for updates

\section{Renan Gomes de} Moura (iD),

Universidade do Grande Rio, Brasil Mestre e Doutorando em Administração, Universidade do Grande Rio, Brasil

renangmoura@gmail.com crans

Rejane Prevot Nascimento (iD),

Universidade do Grande Rio, Brasil Mestre e Doutora em Engenharia de Produção, Universidade Federal do Rio de Janeiro, Brasil

rejaneprevot@uol.com.br 


\section{Introdução}

Tratados muitas vezes como minorias ou excluídos, os homossexuais, assim como outras categorias marginalizadas da sociedade, estão submetidos ao controle social por parte de um grande grupo hegemônico, que determina o que é tido como "normal" (Pereira, 2009).

Nesse sentido, Hassard, Hollyday e Willmot (2000) relatam que as noções de dominação da racionalidade são usualmente percebidas e articuladas àuma concepção tradicional de masculinidade e são sustentadas e valorizadas nas corporações por homens e mulheres. Ressalta-se, de maneira generalizada, que as organizações são ambientes extremamente masculinizados e geridos por homens brancos (Hansen, 2002). Nessa mesma linha de pensamento, Motta (1993, p.69) afirma que as organizações "são as principais responsáveis pelas formas de conduta dos atores sociais". O autor salienta ainda que as organizações são mecanismos que amoldam os indivíduos de acordo com as suas necessidades, em um processo de socialização contínua, pois esse processo perdura por todo tempo em que o indivíduo permanece na organização (Motta, 1993). Diante do exposto, evidencia-se ainda que as organizações funcionam como agentes "normalizadores" de conduta e procuram reforçar padrões de gênero convencionais. Neste ambiente busca-se também reproduzir a visão do homem como o grande provedor, valorizando a figura do "macho" que utiliza todos os seus esforços para o bem dos negócios (Alvesson \& Billing, 2009).

No campo da Administração estudos que abarquem a temática Queer já foram realizados, principalmente na área que envolve a relação de sujeitos Queer e trabalho. Por exemplo, Siqueira e Fellows (2006) conduziram uma pesquisa que tinha como objetivo analisar como a identidade gay consistia em uma problemática para as organizações, uma vez que essas possuíam dificuldades em propor políticas de diversidade que teriam como objetivo reduzir os efeitos da discriminação. Garcia e Souza (2010) em sua pesquisa com homossexuais masculinos que atuavam no setor bancário descobriram que esses sujeitos sofrem discriminação direta e indireta no ambiente de trabalho e constataram a ausência de regras que estabeleçam diversos direitos trabalhistas que são garantidos a sujeitos heterossexuais. Já os achados de Silva, Bastos, Lima, Ferraz e Cabra (2013) mostraram que há tratamento diferenciado por parte das organizações entre heterossexuais e homossexuais, mesmo diante de uma política de gestão da diversidade. Ainda sobre a política de gestão da diversidade, há o estudo de Diniz, Carrieri, Gandra, Bicalho (2013) que revela que há uma dissonância entre o discurso da política de gestão da diversidade e a prática, uma vez que mesmo as organizações que possuem essa política, elas ainda praticam atos de violência contra esses trabalhadores.

Caproni Neto e Saraiva (2018), buscaram discutir masculinidades subalternas no ambiente de trabalho, adotando como sujeitos de pesquisa trabalhadores não heterossexuais e desvelaram que sujeitos que possuem essas masculinidades não hegemônicas estão sujeitos a violência que são legitimadas socialmente, pois essa violência ajuda a manter a "ordem" e o esvaziamento da identidade de sujeitos homossexuais, uma vez que esses 
são culpados por serem "diferentes". Moura (2019) buscou por meio de um ensaio teórico discutir como a masculinidade tóxica impacta diretamente a vida de homossexuais masculinos dentro das organizações. Gomes e Felix (2019) estudaram a identidade homossexual no ambiente organizacional usando a Teoria da Identidade Social para explicar o fenômeno de "sair do armário" organizacional. Nesse contexto, é possível verificar que os Estudos Queer no campo da Administração vêm se consolidando, contudo, grande parte dos estudos não possuem como foco a feminilidade, mas sim políticas de diversidade, masculinidades subalternas e violências contra trabalhadores homossexuais no ambiente de trabalho. Posto isso, busca-se com este artigo contribuir com esses estudos à medida que o fenômeno estudado consiste na feminilidade.

Em um contexto histórico, "o feminino tem sido construído como subordinado ao masculino, o que favoreceu aos homens uma situação de prestígio, privilégio e poder" (Santana, 2010, p.75). Ressalta-se que os estudos de gênero propõem o ser feminino como uma categoria mutável, pois "o próprio gênero se torna um artifício flutuante, com a consequência de que homem e masculino podem, com igual facilidade, significar tanto um corpo feminino como um masculino, e mulher e feminino, tanto um corpo masculino como um feminino" (Butler, 2015, p.24). Neste contexto, a "valorização de uma sexualidade viril, agressiva, materialista e juvenil levou à estigmatização dos afeminados, maduros e velhos, e também tencionou as conexões existenciais" (Simões \& Facchini, 2008, pp. 47-48). Tanto nas organizações quanto na sociedade existe uma rejeição ao que é tido como feminino e os comportamentos associados à feminilidade devem ser evitados, principalmente em homens (Moura, Nascimento, \& Barros, 2017). Moura, Nascimento e Barros (2017, p.10), acreditam que a "rejeição ao feminino seja uma forma de manter o homem heterossexual e macho dominante em sua posição privilegiada dentro da sociedade". Nesse contexto, a inferiorização do feminino é uma questão exclusivamente social (Saffioti, 1987), uma vez que as relações de gênero se agregaram às relações de poder (Scott, 1999, Souza, Corvino \& Lopes, 2013), "trazendo historicamente uma hegemonia do masculino em relação ao feminino na sociedade, o que gerou uma profunda desigualdade de gênero" (Teixeira, Perdigão, \& Carrieri, 2016). O feminino, por meio da figura da mulher, é considerado frágil e inferior (Melo, Cappelle, Mageste, \& Brito 2004). Contudo, neste trabalho, parte-se do pressuposto de que a capacidade de ser feminino não é algo restrito à mulher, considerando que, socialmente, gays masculinos são tratados como seres pertencentes do universo feminino (Moura, Nascimento, \& Barros, 2017). Por conta desse pressuposto, busca-se responder aqui a seguinte questão: Como é compreendida a feminilidade nas organizações na visão de sujeitos gays?

É importante salientar que alguns fatores levaram ao problema de pesquisa exposto no presente artigo, como a discussão desenvolvida no ensaio teórico de Moura, Nascimento e Barros (2017), no qual os autores buscaram abordar o preconceito nas organizações contra sujeitos gays, como decorrência dos traços considerados socialmente como femininos identificados nesses sujeitos. Neste artigo, os autores concluem que a feminilidade é uma característica tida como "negativa" para o mundo organizacional. Outro estudo que levou à pergunta proposta é oriundo das 
conclusões do trabalho de Santos (2015), por meio do qual se constatou que sujeitos gays masculinos que almejam serem aceitos nas organizações devem assumir um padrão heterossexual masculino e, por esta razão, abdicam da feminilidade em prol do trabalho.

Diante da pergunta proposta, esse trabalho tem por objetivo analisar como a feminilidade é compreendida nas organizações, à luz do conceito de estigma, pela perspectiva do próprio sujeito gay, por meio da análise de conteúdo. O presente artigo está organizado da seguinte forma: primeiro discutiu-se a questão do gênero dentro do contexto organizacional, bem como a feminilidade como um artífice do gênero. Posteriormente, discutiu-se o conceito de estigma, a partir do trabalho de Goffman (1978). Na quarta seção, é apresentada a metodologia utilizada e, em sequência, é apresentado o corpus da pesquisa, a análise do corpus e por último as considerações finais.

\section{A questão do gênero nas organizações}

São múltiplos os significados do termo "gênero" apresentados na literatura, tendo em vista que o conceito de gênero é amplo (Alvesson \& Billing, 2009, Saffioti, 2011), e pode ser analisado como uma categoria histórica. Gênero pode também ser uma categoria de análise para aparelhos semióticos, organizações e instituições sociais, contudo, todas convergem para um mesmo ponto: a noção de que gênero se refere à construção social do feminino e do masculino (Saffioti, 2011). Para Butler (2015) o gênero é constituído por um conjunto de "atos" repetitivos no decorrer do tempo, em que não só o gênero, mas também a construção da sexualidade se dá pela repetição de discursos, ou seja, a construção do gênero não deve ser vista como algo que o sujeito criou individualmente para si. Neste sentido, gênero, para Butler, é uma construção social e não determinada biologicamente.

Louro, Felipe e Goellner (2013) apontam que as diferenças entre homens e mulheres ocorrem nas questões socioculturais e não somente biológicas. O conceito de gênero refere-se às relações sociais e de poder entre homens e mulheres, e cada um tem um papel social determinado pelas diferenças construídas socialmente a partir do sexo ao qual acredita pertencer.

Gênero se refere às noções socialmente construídas de o que significa ser um homem ou uma mulher. É útil distingui-lo de "sexo", como as categorias de homem e mulher baseadas na biologia. Esta distinção foi feita nos anos 1960 por feministas que buscavam separar sexo como um "dado' biológico de gênero, visto como um produto de forças sociais e culturais e portanto divorciado de significados determinísticos. Isto ajudou a mudar ideias, prevalecentes naquela época, que arranjos hierárquicos baseados em categorias sexuais eram de alguma forma inevitáveis e "naturais" (ex. Homens são dominantes porque eles são homens, mulheres são subservientes porque são mulheres) Gabriel, 2008, p. 118, tradução nossa).

As relações de gênero evidenciam questões relacionadas ao poder nas organizações, visando legitimar determinados tipos de dominação de coletividades especificas. No meio organizacional, a construção do gênero legitima e delimita os espaços sociais, em que que os envolvidos 
o "jogo de poder" que existe nas relações sociais (Andrade, Cappelle, Brito, Paula Neto, \& Vilas Boas, 2002). Considera-se que, de forma tácita, as organizações não mantêm relações de poder somente sobre as relações de gênero, mas também sobre a sexualidade (Hearn \& Parkin, 2001). Santos e Antunes (2011) relatam que em grande parte das organizações as relações de gênero são um reflexo dos valores da sociedade patriarcal e, desta forma, a categoria gênero no contexto organizacional é mais uma forma de reproduzir a dominação masculina que é refletida da sociedade em sua cultura organizacional.

Conforme já apontado, as organizações adotam como verdade os valores da sociedade patriarcal e, por consequência, reproduzem os padrões de gêneros convencionais (homem/mulher), incentivando e propagando a noção do "ganha-pão-masculino", enaltecendo o homem como o provedor e os orientando para as carreiras e cargos mais valorizados (Alvesson \& Billing, 2009). Considera-se, diante desse contexto, que estudos de gênero compreendem as organizações como ambientes que dialogam com questões de raça, etnia e classe e que promulgam através de suas práticas e manifestações culturais o que é masculinidade e feminilidade no trabalho (Martin, 2011). Para Ely e Meyerson (2000), o gênero nas organizações é enquadrado em duas abordagens distintas, que são classificadas como tradicionais e não tradicionais e se subdividem em quatro outros grupos. As abordagens tradicionais são definidas como: "Treinar as mulheres", "Valorizar o feminino", "Criar igualdade de oportunidades" e "Abordagem não tradicional de gênero".

A primeira abordagem, denominada de "Treinar as mulheres", consiste em uma abordagem mais comum para a igualdade entre os sexos e decorre de uma teoria política, que postula que os indivíduos nascem e morrem por seus próprios méritos. Já a segunda abordagem, "Valorizar o feminino", se opõe à primeira, apesar de sua concepção de gênero continuar a ser baseada nas diferenças biológicas entre homens e mulheres. Essas diferenças não devem ser eliminadas, ao contrário, comemoradas. De acordo com essa perspectiva, a diferença entre mulheres e homens, em particular, seu "sexo-feminino" que tradicionalmente as marcou como inadequadas para determinados trabalhos, na verdade constitui um estilo de gestão eficaz e necessária. A terceira abordagem, denominada de "Criar igualdade de oportunidades" de gênero, consiste na equidade de gênero e enfoca as barreiras estruturais da organização ao recrutamento e avanço da mulher no trabalho (Ely \& Mayerson, 2000). E, por último, mas não menos importante, os autores evidenciam a abordagem denominada "Abordagem não tradicional de gênero". A partir dessa perspectiva, sexo não é uma característica individual, nem simplesmente uma base para a discriminação. Pelo contrário, ele é descrito como um conjunto complexo de relações sociais, promulgadas em toda uma gama de práticas sociais que existem dentro e fora das organizações formais (Ely \& Mayerson, 2000).

Diante do exposto, percebe-se que em muitas organizações as questões referentes a gênero estão enraizadas em fatores biológicos, no binarismo mulher/homem, fêmea/macho, porém já se percebe a emergência de abordagens que questionam a construção da ideia de gênero ou ainda do que é ser masculino ou feminino dentro das organizações. 


\section{O que é feminilidade (ou "feminilidades")?}

Dentre os vários conceitos existentes sobre feminilidade, um deles é ancorado na Sociologia e na Antropologia dos sexos. Para essas áreas, "masculinidade e feminilidade designam as características e as qualidades atribuídas social e culturalmente aos homens e às mulheres" (Molinier \& Welzer-Lang, 2009, p.101). Santos (2010, p.842) observa "que feminilidade e masculinidade estão em permanente transformação, não sendo determinações fixas, e possuem uma multiplicidade de formas de ser homem ou mulher". No que tange à feminilidade, pode-se dizer que é um termo usado para descrever igualmente os principais recursos da sexualidade feminina e as características atribuídas ao feminino (Gabriel, 2008). A feminilidade não é uma essência, mas sim uma construção cultural, não sendo singular, mas sim plural. Logo, pode-se afirmar que existem feminilidades, tendo em vista que não existe um modelo a ser seguido e tampouco essa característica é privilégio somente das mulheres (Connel, 2003, Veiga, 2012). Partindo-se dessa perspectiva, pode-se afirmar que todos os indivíduos possuem dentro de si os princípios femininos e masculinos (Veiga, 2012), "é por essa mistura de masculino e feminino em nosso organismo (corpo) que existe essa diversidade maravilhosa entre os seres humanos e todos os outros seres vivos" (Muraro, 2007, p. 30-31). Embora os conceitos de masculinidade e feminilidade não sejam autodefendidos, por se tratar de uma construção social, cultural, histórica e geograficamente contextualizáveis, a sociedade assimila e cria expectativas em relação aos comportamentos ligados à feminilidade, associando-os unicamente às mulheres (Veiga, 2012).

Os comportamentos então associados à feminilidade são aqueles percebidos e ligados ao domínio do lar, às virtudes morais, à emotividade, à limpeza e aos trabalhos sociais (Eccel \& Grisci, 2011). Os valores femininos ou o princípio feminino caracteriza-se pela interdependência, cooperação, receptividade, aceitação, reconhecimento de padrões, tom emocional, percepção e intuição (Alvesson \& Billing, 2008).

Para alguns autores, como Butler (2015), assim como existem diferentes masculinidades, também não podemos afirmar a existência de uma "feminilidade", mas sim, de vários tipos de "feminilidades". As feminilidades e as masculinidades são dimensões que estão associadas aos papeis de gênero estabelecidos pelas normas socioculturais, porém o termo mais adequado seria performatividade (Butler, 2015). Para a autora, a performatividade "deve ser compreendida não como um 'ato' singular ou deliberado, mas, ao invés disso, como a prática reiterativa e situacional pela qual o discurso produz os efeitos que ele nomeia" (Butler, 2015, p. 111). Souza, Bianco e Junquilho (2015) expõem que muitos estudiosos de gênero tendem a considerar a feminilidade como uma característica inerente à mulher, contudo, tais características são aprendidas, e não inatas. Nesse sentido, pode-se dizer que o "ser" feminino constitui-se, na verdade, da performance do feminino. Ressalta-se ainda que o gênero não é dado ao indivíduo, pois de acordo com Butler (2015), é na superfície do corpo que atos, gestos e desejos são incorporados e são entendidos, de forma plural, como performativos, pois a essência da identidade que pretendem 
expressar as fabricações manufaturadas e sustentadas por símbolos corpóreos e meios discursivos. Nesse sentido, o gênero performativo não possui uma posição ontológica separada de vários acontecimentos que constituem a sua realidade. A performance é similar ao ato performativo, contudo a primeira é ancorada em questões cunhadas na realização individual. Já os atos performativos estão vinculados às noções aplicadas a discursos coletivos que possibilitam a construção do gênero (Butler, 2015). Nesse sentido, Louro destaca que:

Performativos de gênero são repetidos constantemente. Citados e recitados em contextos e circunstâncias distintas; no âmbito da família, da escola, da medicina; na mídia, em suas mais diversas expressões; nas regulamentações da justiça ou da religião. Não obterão, contudo, os mesmos resultados. Os efeitos dos performativos são sempre imprevisíveis. [...] A falha, que é intrínseca aos performativos, pode ser produtiva. É na possibilidade do fracasso que reside o espaço para a ressignificação e para a subversão no terreno dos gêneros e da sexualidade (Louro, 2013, p. 33).

É importante ressaltar que tanto Butler (Salih, 2015) quanto Louro (Louro, 1997) são influenciadas pelo pós-estruturalismo e ambas afirmam que a feminilidade se opõe à noção de masculinidade. Para as autoras o ideal de feminilidade é aquele enraizado no feminino heterossexual, ligado à passividade e à fragilidade. Embora Butler tenha sido fortemente influenciada por filósofos da escola pós-estruturalista, a filósofa também possui influências da psicanálise, das teorias feministas e do marxismo (Salih. 2015).

Butler (1993) relata que o gênero performativo é além daquilo que se define como relações de gênero. O gênero, então, é performativo, pois vai construindo-se nos indivíduos com o tempo. Para a autora, não é sujeito que cria o gênero, mas sim o gênero que possibilita a existência do sujeito e isso só ocorre em um longo processo de construção do gênero e da própria identidade. "O gênero é performativo porque é resultante de um regime que regula as diferenças de gênero. Neste regime os gêneros se dividem e se hierarquizam de forma coercitiva" (Butler, 2015, p. 64). De uma forma resumida, podemos dizer que a teoria da performatividade tenta entender como a repetição das normas, muitas vezes feita de forma ritualizada, cria sujeitos que são o resultado dessas repetições. Assim, quem ousa se comportar fora dessas normas que, quase sempre, encarnam determinados ideais de masculinidade e feminilidade ligados à uma união heterossexual, acaba sofrendo sérias consequências. Nesse sentido, não se pode dizer que gênero é o que os indivíduos são, mas sim o que os indivíduos fazem, sendo uma sequência de atos. Ou seja, o gênero é um conjunto repetitivo de atos que são vinculados à modelos regulatórios e rígidos, sendo assim, o gênero é constituinte da identidade que as pessoas pretendem ser. Logo, o gênero é sempre um fazer (Salih,2015).

A partir dessas definições percebe-se que existe uma grande relação entre gênero e feminilidade, tendo em vista que os gêneros operam através da matriz heterossexual, solicitando aos sujeitos a incorporação de características que idealizam as feminilidades, ou seja, a matriz estabelece a essas incorporações as formas pelas quais o gênero deve ser performado (Butler, 1993). 


\section{Estigma}

O conceito de estigma é ainda pouco utilizado para a análise das questões relacionadas à gênero, sendo frequentemente associado aos estudos sobre obesidade (Wellman, Araiza, Solano, \& Berru, 2019; Melo, Faria, \& Kovacs, 2017), sobre doença mental (Barretto \& Figueiredo, 2019; Collins, Wong, Breslau, Burnam, Cefalu, \& Roth, 2019; Abramenko, Lovisi, Fonseca, \& Abelha, 2017) e sobre o HIV/AIDS (Casétte et al., 2016; Villela \& Monteiro, 2015). Segundo Goffman (1978), o termo "estigma" foi criado pelos gregos para se referir àqueles sujeitos que tinham seus corpos marcados por fogo ou corte, a fim de designar de forma negativa sua moral e seu status social. Assim, o indivíduo marcado deveria ser repudiado e evitado em todos os espaços, principalmente nos lugares públicos. Nesse sentido, toma-se por noção preliminar que a sociedade estabelece diversos meios para classificar as pessoas e classes de acordo com os atributos que possuem em comum, sendo essas classificações definidas pelo próprio ambiente social (Goffman, 1978).

Nesse contexto, a sociedade funciona como elemento regulador, que limita e delimita a capacidade de ação daqueles que são estigmatizados, marcando-os como desacreditados e mostrando os efeitos "maléficos" que eles podem representar: "o social anula a individualidade e determina o modelo que interessa para manter o padrão de poder e anula todos os que rompem ou tentam romper com o modelo social" (Melo, 2000, p. 2). Nesse sentido, compreende-se que os atributos estigmatizadores produzem "discriminação, preconceito e exclusão social do indivíduo", como afirmam Melo et. al, 2017, p. 2), em seu estudo sobre o estigma da obesidade.

A ideia de estigma é decorrente da noção de desvio e da existência de indivíduos "normais" e aqueles considerados "desviantes". A identificação de uma dessas categorias estaria, necessariamente, relacionada com a identificação da outra, em uma relação de definição por contraste ou oposição, conforme afirma Goldwasser (2012).

Martin (1986) relata que o estigma se perpetua através da aprendizagem social, a qual está relacionada "às características e aos fatores associados à aprendizagem social de estigma; à aprendizagem social no decorrer da vida; à relação de aprendizagem social para o desenvolvimento de crenças; à atitude; aos valores; e à maneira que as pessoas avaliam os outros" (1986, p. 146). O autor ressalta ainda que a aprendizagem social não é apenas uma ferramenta eficaz de manutenção e aquisição de comportamentos que permitam a estigmatização de pessoas, mas também um mecanismo através do qual os indivíduos percebem, esperam e aprendem quais são os comportamentos daqueles que são estigmatizados (Martin, 1986).

Becker e Arnold (1986) relatam que o estigma geralmente é compartilhado pelos membros de uma sociedade. Eles aprendem crenças comuns sobre o significado cultural de um atributo e o estigma associado a ele, portanto, as crenças sobre estigma determinam a sua natureza. Embora o conceito de estigma seja universal, as percepções do que constitui o estigma variam de uma sociedade para outra. Isso se deve a estruturas, valores e normas culturais diferentes (Becker \& Arnold, 1986). No que tange 
ao comportamento dos sujeitos estigmatizados, Goffman (1978), relata que essas pessoas demandam grandes esforços individuais para tentar "corrigir" a condição que faz com que sejam estigmatizados. Contudo, muitos dos sujeitos estigmatizados utilizam as privações advindas do estigma como um ensinamento, pois acreditam que o sofrimento pode ensinar sobre as outras pessoas e até mesmo sobre a vida (Goffman, 1978). Nesse raciocínio, Melo (2000), relata que os sujeitos estigmatizados ocupam um papel social fundamental na vida daqueles ditos "normais", pois servem de modelos de referência de como não se deve ser.

Pépece e Miranda (2019), em seu estudo sobre a construção da identidade de gênero a partir de uma análise fílmica, apontam que o universo feminino é frequentemente associado ao estigma da fragilidade e da fraqueza (p. 58). Tais características, nos seres femininos, são identificadas como elementos de inferiorização. Para além da inferiorização, Velho (2003, apud Pépece \& Miranda, p. 62) afirma que, para os indivíduos que são estigmatizados, carregar um estigma é como ser submetido à uma acusação.

Leão e Mello (2011) identificam três tipos de estigmas, sendo eles: comunal, social e pessoal. Os estigmas comunais são aqueles oriundos da esfera cultural e estão relacionados à noção de pertencimento dos indivíduos, podendo ser pertencimento de localidade ou de grupo. Os estigmas de pertencimento de localidade são aqueles referentes à nacionalidade ou local de origem do indivíduo. Já os estigmas de grupo abarcam características comuns a certos indivíduos que compartilham dos mesmos interesses. O segundo tipo de estigma descrito por Leão e Mello (2011) é o estigma social. Esse tipo de estigma inclui questões relacionadas à condição social e ao gênero das pessoas. No que tange especificamente ao estigma de gênero, este é relacionado às noções pejorativas referentes à masculinidade e à feminilidade. Os estigmas de gênero são enraizados em práticas machistas e atribuem ao universo feminino e aos homens afeminados características negativas.

Por último, os autores definem o estigma pessoal. Esse tipo de estigma refere-se unicamente aos aspectos individuais e envolve questões atreladas às características pessoais ou a algum comportamento adotado pelas pessoas que entre em confronto com o que é esperado desse indivíduo na vida pública (Leão \& Mello, 2011).

\section{O percurso metodológico}

O corpus da pesquisa (Bauer \& Aarts, 2015) foi composto pelas transcrições das entrevistas realizadas com sujeitos gays que estavam inseridos no ambiente organizacional, de modo a explorar se ocorre e como ocorre a estigmatização da feminilidade. A seleção dos sujeitos de pesquisa foi feita pela cadeia de referência, ou seja, por meio da indicação dos próprios entrevistados. Para isso, a técnica utilizada para recrutamento dos sujeitos de pesquisa foi a snowball, também conhecida como snowball sampling (Biernacki \& Waldorf, 1981). O método utilizado para a produção do corpus da pesquisa foi o método de entrevistas individuais em profundidade, tendo em vista que esse método permite a reformulação de perguntas em busca de um maior entendimento sobre o corpus, possibilitando, assim, 
a emergência de achados ainda não encontrados na literatura (Dresch, Lacerda, \& Antunes, 2015).

O tipo de análise de corpus escolhida para o presente trabalho consistiu na Análise de Conteúdo, proposta por Bardin (2006). Observa-se que "a análise de conteúdo é um conjunto de técnicas de análise de comunicações, que tem como objetivo ultrapassar as incertezas e enriquecer a leitura dos dados coletados" (Mozzato \& Grzybovski, 2011, p.734) que pode "compreender criticamente o sentido das comunicações, seu conteúdo manifesto ou latente, as significações explícitas ou ocultas" (Chizzotti, 2006, p. 98).

Nesse contexto, Bardin (2006, p. 43) afirma que "a análise de conteúdo toma em consideração as significações (conteúdo), eventualmente a sua forma e a distribuição destes conteúdos e formas (índices formais e análise de co-ocorrência)". A análise foi realizada segundo as três fases de Bardin (2006), sendo elas: 1) pré-análise, 2) exploração do material e 3) tratamento dos resultados, inferência e interpretação.

A pré-análise consistiu na transcrição e leitura do corpus da pesquisa e da seleção dos fragmentos para análise. A segunda fase consistiu na categorização dos trechos das falas a partir das seguintes categorias: estigma, feminilidades e gay afeminado. E, por fim, foi realizado o tratamento e a interpretação do corpus da pesquisa.

Foram entrevistados nove (09) sujeitos gays masculinos assumidos, residentes no estado do Rio de Janeiro, com idades entre 21 e 46 anos, atuando como profissionais nas mais diversas áreas, com diferentes níveis de formação, tais como, jornalistas, estagiários, coordenadores de curso (nível graduação), supervisores financeiros, entre outros. Foram entrevistados funcionários de organizações públicas e privadas de diversos segmentos. As entrevistas duraram em média uma hora e vinte minutos e foram todas transcritas, gerando o corpus dessa pesquisa. A pesquisa se encerrou com nove sujeitos, pois a saturação foi alcançada com esse número de entrevistas. Nesse artigo a saturação não é entendida da mesma forma como o é nas pesquisas quantitativas, mas sim usada pela perspectiva qualitativa, segundo a qual "as ferramentas utilizadas na constatação de saturação não são de ordem matemática, e sim cognitiva (envolvendo a percepção do pesquisador e seu domínio teórico)" (Fontanella, Ricas, \& Turato, 2008, p.24).

\section{Apresentação e análise do corpus da pesquisa}

Nessa seção apresenta-se o corpus produzido, separado por temas que correspondem às categorias a priori investigadas na pesquisa de campo, assim como a análise do corpus a partir do referencial teórico da pesquisa.

\section{O estigma da feminilidade nas organizações}

Os entrevistados foram questionados sobre o estigma de ser feminino a partir de diferentes questões sobre o tema. A primeira questão buscava identificar como o feminino é visto tanto na sociedade quanto nas organizações. As respostas obtidas confirmam o que já foi apontado por Pépece e Miranda 
(2019) sobre a estigmatização do feminino a partir de sua identificação com características tais como fragilidade e fraqueza, tendo como consequência a sua inferiorização na sociedade. Para um dos entrevistados, as características associadas ao feminino são vistas como próprias de indivíduos "frágeis": "O feminino sempre foi visto, e está longe de parar de ser visto como o sexo frágil. Sempre foi, até hoje é" (Lucas). Um dos relatos associam o feminino como um elemento de inferioridade no ambiente de trabalho: "Como você vê, analisar uma questão histórica ou... você sabe que o feminino sempre foi subjugado no ambiente de trabalho" (Taric). Percebe-se que o feminino sempre foi tido como inferior no ambiente de trabalho e esse fato não é apenas uma característica do passado, mas também dos dias atuais. Subjugar o feminino no ambiente de trabalho é uma herança histórica que se estende até os dias de hoje. Quando abordado especificamente sobre como o feminino é visto nas organizações, um dos sujeitos relatou que ele está atrelado a questões como: "trabalho, familia... Muito mais pejorativo, muito mais discriminador, muito mais sofrido para ele, entendeu..." (Nathan). Dito isso compreende-se que o feminino ainda continua sendo visto como relacionado às características ligadas às atividades do lar e também como alvo de preconceito. A visão dos entrevistados se alinha como o que é identificado no trabalho de Eccel \& Grisci (2011), sobre a feminilidade estar associada às tarefas limitadas ao domínio do lar. Tal característica acaba por marcar ou estigmatizar os seres femininos como não adequados para o ambiente organizacional, na medida em que suas habilidades e mesmo a sua personalidade ("frágil") se ajustam ao espaço privado, do lar. O entrevistado Nathan retrata o feminino como característica de indivíduos submissos, sem força, com uma imagem a qual o entrevistado busca se afastar, conforme a narrativa a seguir:

\begin{abstract}
É a questão de perder o pulso, a gente sabe que faz parte de um grupo de convivência, sabe que não tem pulso nenhum entendeu, seu eu for falar com a minha mãe, minha patroa, meu companheiro a gente não tem pulso e nem muda nada, nem a própria vida, nem o tempo, quanto mais o outro, e tenta dominar si próprio. É um erro meu, quando eu tô próximo do feminino tento mudar a roupa, boto outra coisa, uma combinação que vai me colocar uma visão um pouco mais jovem, me incomoda também, tento disfarçar, eu não consigo ficar perto dentro do feminino não, eu tiro a carapaça que esteja se aproximando de algo que seja muito feminino, a figura feminina da minha mãe ela é presente até hoje, mas me incomoda o fato que eu tenha, ou posso estar próximo (Nathan).
\end{abstract}

O relato destacado exemplifica um aspecto já mencionado na revisão teórica deste artigo, a questão da performatividade (Butler, 2015). O entrevistado identifica explicitamente em suas atitudes um comportamento diferenciado quando se trata de sua relação com a mãe, a patroa e o companheiro, posto que essas figuras são associadas ao feminino, o que torna suas atitudes com estes indivíduos sem "pulso", e o que o leva ao esforço de "tentar dominar a si próprio'(o que podemos interpretar como tentar "dominar" suas atitudes "femininas"). Adiante, o entrevistado associa seu comportamento à "figura feminina" da mãe, revelando um incômodo de não conseguir desvencilhar-se dessa figura e da feminilidade a ela associada. Butler (2015) assinala que a performatividade de gênero não é dada ao indivíduo, mas se expressa por meio das atitudes, dos gestos, dos atos e na superfície do corpo. Neste sentido, a tentativa do entrevistado de "tentar dominar a si mesmo" também seria parte da construção da sua identidade. 
Quando questionado sobre como o feminino é visto nas organizações, o entrevistado Luke relata que o feminino é tratado como algo anômalo: "Deve ser visto como bicho né; porque as pessoas hoje em dia preferem pegar uma pessoa mais masculino do que feminino". A associação do feminino como algo "anômalo" pelo entrevistado nos remete à análise de Goldwasser (2012), na medida em que essa atribuição só pode ser compreendida a partir da comparação entre os indivíduos considerados "normais" pela sociedade. Outro aspecto importante a ser observado diz respeito à atribuição de uma "anomalia" aos homens feminilizados ("preferem pegar uma pessoa mais masculino do que feminino"), reiterando um preconceito bastante reproduzido na sociedade contra os indivíduos homossexuais, categoria da qual o próprio entrevistado faz parte. Deve-se notar que esse mesmo entrevistado afirma ser "ora feminino, ora masculino". Para o entrevistado Jordan, as características femininas podem acarretar problemas para quem as possui: "O feminino em geral... Bem eu acho que isso já mudou muito, mas é claro que exista ainda um problema com questão de gênero dentro das empresas, dentro das organizações [...]". De acordo com Jordan isso acarreta para os indivíduos femininos: "Uma condição subalterna. Uma condição que não está envolvida no processo decisório. Uma condição que acaba sendo, de certa forma, preterida. Acho que esse é o grande problema". No contexto organizacional, de acordo com a fala do entrevistado Lucas, o feminino é tido como algo que chama atenção demasiadamente, seja em homens ou mulheres nas organizações: "É visto como escandaloso [...]A mulher vai ficar fazendo aquele trabalho feminino, delicadinho, mas nada em posição de comando".

A fala de Lucas denota o incômodo provocado não apenas pelas características ditas femininas, mas também por seus corpos. O controle sobre os corpos, como verificado nas organizações, ocorre por meio da estigmatização dos sujeitos tidos como seres femininos. Entende-se, a partir do corpus obtido, que as características associadas à feminilidade tornam as mulheres mais vulneráveis e por isso consideradas incapazes para posições de comando. Dito isto, infere-se que por meio das organizações a dominação exclui a mulher da vida pública, em específico do trabalho, e a coloca na vida privada, na medida em que associa a feminilidade aos cuidados da casa. Ressalta-se que essa visão é compartilhada até mesmo pelos sujeitos gays entrevistados. Evidencia-se, de modo geral, que há por parte das organizações uma rejeição à feminilidade, seja ela em um corpo masculino ou um corpo feminino. A feminilidade nas mulheres faz com que sejam vistas como sujeitos "impróprios" para realizar determinadas tarefas nas organizações, pois as características socialmente associadas à feminilidade marcam as mulheres como seres menos capazes. Butler (2015) relata que os traços associados à feminilidade são tidos como inferiores. Percebe-se que a feminilidade é tratada, no âmbito organizacional, como um estigma, que marca socialmente algo frágil e subjugado, ou ainda que está sob a égide do poder masculino.

Além das questões associadas à personalidade e aos corpos femininos, emergem nos relatos dos entrevistados as visões sobre a capacidade profissional das mulheres, como consequência das características anteriormente citadas. De acordo com o entrevistado Vinicius, existe, por parte da sociedade, uma restrição aos indivíduos femininos, pois são julgados como "menos capazes": 

está pronta para isso, tanto que ela não aceita. Eu acho que assim, é... Infelizmente o preconceito é muito grande, as pessoas não entendem muita coisa, levam para um lado que não existe e infelizmente as oportunidades não existem para esse grupo. Porque as pessoas não conseguem diferenciar o pessoal do profissional. Porque existe esse padrão do homem, da mulher, do másculo, do feminino (Vinicius).

Esta visão também se manifesta no fragmento da fala do entrevistado Rodrigo: "Eu acho que em parte que o comportamento afeminado está associado a mulher, e muitas pessoas consideram mulher como menos capaz, ou então menos apta a fazer alguma coisa, então, isso pode estar relacionado, talvez". Com esse fragmento percebe-se que a visão do feminino foi construída socialmente como associada ao indivíduo menos capaz, por ser vinculado à figura da mulher. Nesse relato também se evidencia que a mulher, tal como vista socialmente, não possui capacidade para realizar algumas tarefas. Além disso, ao associar as mulheres às atividades domésticas e de cuidados, é atribuído a ela socialmente uma responsabilidade por atividades consideradas menos complexas e menos valorizadas socialmente, em detrimento de atividades com maior exigência de complexidade ou capacidade de decisão e responsabilidade, historicamente encaradas como masculinas, como já observado por Alvesson e Billing (2008), e Eccel e Grisci, (2011). Sendo assim, pode-se concluir que não só a sociedade, como também as organizações, funcionam como elementos reguladores, os quais delimitam e limitam as capacidades dos sujeitos femininos. Neste sentido, Melo (2000) afirma que os sujeitos estigmatizados ocupam um papel social fundamental na vida daqueles ditos "normais", pois servem de modelos de referência de como não se deve ser.

Como relata um dos entrevistados, o feminino nas organizações é algo pejorativo, ou seja, algo insultuoso ou até mesmo depreciativo e desagradável. Tal fato mostra que esses sujeitos são marcados como inferiores por possuírem uma característica em comum: a feminilidade. Tal fato tem como consequência a estigmatização desses indivíduos, pois há uma relação de atribuição da inferioridade ao "ser feminino" com a estereotipação, como já foi exposto nas ideias de Goffman (1978) sobre estigma.

Observou-se ainda que as organizações estigmatizam a feminilidade a partir do momento em que o feminino está em uma condição preterida, ou seja, desprezado e rejeitado. Infere-se que seres femininos estão nas organizações para cumprir ordens, conforme relata um dos sujeitos. Pode-se dizer que gays afeminados e mulheres são estigmatizados por pertencerem a um mesmo grupo, o "ser feminino" e/ou "possuir feminilidades". Com isso, compartilham de um estigma comunal, alinhando-se assim ao aspecto abordado por Leão e Mello (2011) no que se refere aos estigmas comunais como relacionados à noção de pertencimento dos indivíduos.

Verifica-se, a partir desses relatos, que as características ligadas ao feminino são encaradas no ambiente organizacional como algo que inferioriza os sujeitos, são vistas como próprias de indivíduos mais frágeis e, em alguns casos, podem suscitar reações de preconceito ou rejeição. Em outros relatos, os entrevistados percebem que, nas organizações, as características femininas estão vinculadas à incapacidade. 


\title{
O estigma do gay afeminado nas organizações
}

Nesta seção serão discutidos os relatos que abordam como o gay afeminado é estigmatizado por parte das organizações.

\begin{abstract}
A sociedade vê o homossexual como a bichinha frágil, se for para ganhar a vida, para todos eles o viado ele é subjugado, não só pela sociedade, pela família, pela escola. Então, o local de trabalho é preciso ter uma modificação desse tipo de paradigma é preciso derrubar. Até porque eu não dou abertura para ninguém fazer isso (Nathan).
\end{abstract}

Na fala do entrevistado Nathan percebe-se que o gay, de modo geral, é estigmatizado por diversas instituições, como a escola e família. As organizações, enquanto produtos de um contexto social e cultural, parecem reproduzir essa estigmatização. Essa reprodução está ligada ao que Martin (2011) entende como produto da aprendizagem social, posto que para esse autor o estigma é decorrente deste processo de aprendizagem, pois é reiterado e compartilhado pelos indivíduos e norteiam a avaliação que fazem um dos outros. Becker e Arnold (1986) afirmam ainda que a visão sobre os atributos associados a um estigma é em geral compartilhada por toda a sociedade. Nos trechos a seguir são relatadas situações em que o estigma é percebido pelos entrevistados: "Sim, existe preconceito, existe. Não é porque trabalho em banco, que não vou dizer que não tem não. Tem sim, tem. É... eu falei assim: "poxa não vai rolar!" (Vinicius). E para o entrevistado Tiago: "Eu acho que as pessoas ficam pensando que a gente não tem capacidade de resolver certos tipos de coisas, só porque a gente é gay e não tem condições de exercer certas funções".

A noção de que o homossexual afeminado não reúne as características necessárias para exercer funções nas organizações está presente na fala de diferentes sujeitos, assim como a visão de que existem profissões "não adequadas" para sujeitos gays. Tal fala alinha-se com a visão atribuída à capacidade profissional dos demais seres femininos, incluindo as mulheres, conforme já discutido na seção anterior. Seria como se os gays afeminados fossem "contaminados" pelo estigma atribuído ao feminino de um modo geral pela sociedade ou ainda, como afirma Velho (2003, apud Pépece \& Miranda, p. 62), possuir esse atributo assemelha-se a algum tipo de acusação contra quem o possui e, neste caso específico, a acusação refere-se ao fato de ser gay e afeminado. Percebe-se que até como uma estratégia de autopreservação em relação ao preconceito e ao estigma, os sujeitos naturalizam a noção de que algumas profissões "não servem" para gays afeminados, como explicitado no relato a seguir:

É, (ele disse) que não existe gay advogado. O que eu mais vejo hoje em dia é gay advogado. O gay tem que ser homem. Inclusive outro dia eu participei de uma audiência que o juiz era um gay mais afeminado que eu, você falava com o juiz você via no semblante dele, um rapaz novo, provavelmente era um estagiário, não tinha idade para ser juiz, como você mas um pouco mais novo. E assim, eu me achei ali nele. Porque você via que ele era gay. Como eu sou estagiário eu ainda não posso me impor durante uma audiência, mas eu participo, vou, escrevo, mas não posso me impor, não tenho fala, não tenho voz. E eu saí dali assim, encantado com aquilo. Aí eu cheguei pra ele e falei, você disse que não existia gay advogado, mas o juiz era gay, e aí? Aí ele "ah, mas pra você se impor numa audiência você tem que ter voz, você tem que ser homem" (Antônio). 
Um outro fragmento mostra que o gay afeminado não é estigmatizado somente por homens, mas também por mulheres, as quais, segundo um entrevistado, debocham dos comportamentos femininos dos gays, imitando seus trejeitos ou mesmo tratando o gay afeminado ao utilizar pronomes femininos. O entrevistado, embora afirme se considerar afeminado, usa em seu relato um tom pejorativo, ou seja, ele próprio considera o feminino como uma característica que pode ser ironizada:

\begin{abstract}
Vejo meninas, vejo mais meninas debocharem. Meninos não, meninas imitam o jeito deles falarem, tem um menino lá mais afeminado, as meninas gastam ele o dia inteiro pela maneira como ele fala com o cliente, porque ele gesticula, da maneira que ele senta mantendo a postura, elas falam "Ai nem eu faço isso o dia inteiro, mas ele fica lá toda mocinha o dia inteiro". De alguma maneira incomoda. É, incomoda, incomoda é a palavra (Lucas, grifo dos autores).
\end{abstract}

Ressalta-se que o entrevistado Lucas, embora aponte a estigmatização direcionada aos afeminados por parte de homens e também mulheres, parece naturalizar o preconceito identificado nas organizações. Tal comportamento denota o que já foi apontado nesta análise a respeito da noção de aprendizagem social do estigma (Martin, 2011), queé compartilhada também por sujeitos gays, embora sejam eles uma das principais vítimas deste preconceito:

Foi o que eu falei, o gay afeminado puxa mais para o feminino, ele não puxa muito para o lado masculino. Já o gay não, tem muitos amigos que trabalham em grandes escritórios, grandes empresas, que são gays, mas não são afeminados, e tenho um amigo meu afeminado, o único amigo meu afeminado, que ele foi para uma entrevista de emprego [...] ele foi para uma entrevista de emprego de colar, brinco, o jeito dele, aquelas roupinhas dele super apertadas e na hora da entrevista falou, a gente não escolhe esse padrão pra nossa empresa. Aí ele conversou muito comigo, ele queria até entrar com um processo contra a empresa, porque ele disse que foi um preconceito, mas na verdade não foi, apenas a pessoa foi sincera dizendo que a empresa não trabalha com esse tipo de padrão. É gay, é gay, a empresa tem até gay porque eu já entrei lá, é a $X X X X$, a empresa tem até gay, mas afeminado não tem, tem gay hétero, mas não tem gay afeminado. Porque é uma empresa multinacional, você tem que lidar com pessoas de fora, a área dele seria a área de importação de veículos, vindo de fora pro Rio, então é uma área que abrange dezenas de pessoas de fora, e ele não ia conseguir, eu disse pra ele, [...] você é uma pessoa que não ia se enturmar lá, até mesmo por causa do preconceito, lá tem muito homem. E um gay afeminado não fica onde tem muito homem (Antônio, grifo dos autores).

Observa-se, a partir dos relatos anteriores, que os entrevistados, apesar de perceberem o preconceito, a ironia e o deboche contra os sujeitos afeminados, acabam concordando que os indivíduos femininos, sobretudo os gays, são inadequados para o ambiente organizacional. Ao relatar o preconceito ocorrido com um amigo no processo de seleção, percebe-se que o sujeito Antônio não consegue identificar a estigmatização do gay afeminado. O entrevistado afirma que "a pessoa ao menos foi sincera", o que denota uma tentativa de justificação do preconceito do empregador. Pode-se ainda constatar que o sujeito naturalizou o estigma ao utilizar-se de um discurso de justificação para tal ato. Outro elemento evidenciado na fala do entrevistado Antônio é o fato da empresa ter preferência em contratar gays com comportamentos heteromasculinos. 
Quando questionados sobre a aceitação do gay em qualquer tipo de organização, os entrevistados, de um modo geral, indicam que a estigmatização do gay afeminado ocorre em diversos tipos de organizações, e mesmo com os avanços no campo dos direitos que esse grupo tem conseguido nos últimos anos, ainda há um caminho a percorrer no sentido de diminuir o preconceito. Um relato que que chama atenção é o do entrevistado Lucas, conforme a seguir:

Porque não é uma mulher, entendeu? Ele não é uma mulher, então é algo que está fora do padrão, não para mim, mas é algo que está fora do padrão. Pra grande maioria. Isso eu não falo só na questão de empregador, mas de estética por isso que eu falo que é mais difícil um gay feminino conseguir qualquer coisa em qualquer lugar. (Lucas).

Percebe-se, a partir do relato, que o gay afeminado é visto como um "ser estranho" por não corresponder aos padrões comportamentais masculinos estipulados e quando o mesmo externaliza sua feminilidade, torna-se motivo de repressão por parte das organizações e da sociedade.

A partir dos relatos apresentados, pode-se considerar que o ato de "entrar no armário organizacional" e adquirir comportamentos heteromasculinos não são apenas atos de submissão à dominação masculina, mas também são um esforço para tentar prevenir os comportamentos que os fazem ser estigmatizados pelas organizações. Tal reação às práticas estigmatizadoras já foi constatada por Goffman (1978), ao afirmar que os sujeitos estigmatizados demandam grandes esforços individuais para tentar corrigir a condição que faz com que sejam estigmatizados. Foi identificado, a partir do corpus produzido, que as organizações são instituições que controlam os corpos do seu quadro de pessoal no que tange aos corpos feminilizados. Tal controle foi identificado a partir do momento em que os sujeitos relatam que sofrem com o deboche ou a rejeição nesse ambiente. Evidenciou-se, ainda, que dependendo das organizações, até as mulheres têm que abdicar de sua feminilidade para também serem aceitas no trabalho.

Já o gay afeminado é considerado como um ser ao qual as organizações não querem associar a sua imagem, conforme é explicitado no relato de um dos entrevistados (Antonio), ao exemplificar utilizando o caso de uma empresa multinacional. Observou-se que esses sujeitos são marcados por tentarem, às vistas dos colegas de trabalho, "ser mulher". Infere-se que os gays afeminados experimentam a feminilidade através de seus corpos e é exatamente essa expressão feminina em um corpo biológico masculino que faz com que esses sujeitos sejam considerados como uma imagem negativa para as organizações.

Os entrevistados foram questionados ainda se já foram punidos pelo fato de serem gays ou por serem afeminados. Um dos entrevistados relata que por ser gay e afeminado não foi promovido em seu trabalho há mais tempo por conta da resistência dos seus superiores: "Eu noto que a resistência a mim ao longo do tempo diminuiu muito, isso eu acho que a gente sente com muita clareza. Eu por exemplo, não seria coordenador há 10 anos atrás" (Jordan). O entrevistado atribui isso ao fato de ser gay, pois relata ter sido indicado para o cargo algumas vezes e em todas foi preterido: "eu fui indicado várias vezes e nunca fui aceito. Porque eu acho que tem a ver com o fato de ser gay" (Jordan). Por meio de sua fala percebe-se que ele sofreu 
restrições por ser gay durante vários anos, como ele mesmo menciona. O mesmo entrevistado acrescentou que é alvo de preconceito, principalmente por meio de deboche. Tal sentimento é relatado por outros entrevistados:

\begin{abstract}
Já. Já imitaram o meu jeito de ser, de andar, até mesmo de lidar com as pessoas, mas eu sou uma pessoa muito estressada e eu jogo pra ganhar. Eu falei "gente, eu não gosto de brincadeiras, eu não sou obrigado a sofrer isso, porque é preconceito querendo ou não, eu não gosto de apelido, eu não gosto de ficarem me imitando. Meu jeito é esse, quem quiser me aceitar me aceite, quem não quiser que morra, que eu não estou nem aí (Antônio).

Assim, eu me recordo assim de uma vez um cara fazendo um comentário, uma piadinha mesmo em relação ao fornecedor que trabalha com a gente lá, que, foi lá fazer uma reunião, e no momento em que ele foi embora, ele fez uma imitação mostrando o quão viado ele era (Rodrigo).
\end{abstract}

A partir dos relatos pode-se observar que o gay afeminado, em qualquer estágio da vida, poderá sofrer ou ser rejeitado, tanto pelas organizações quanto pela sociedade. Tal fato revela que esses sujeitos são estigmatizados e, em dado contexto, são marcados pelo estigma social. Sendo assim, esse estigma é enraizado nas noções pejorativas referentes à masculinidade, ou seja, esses indivíduos são marcados de forma negativa, atestando, assim, as ideias de Leão e Mello (2011), ao evidenciar o estigma de gênero.

Conforme apresentado nos relatos, no ambiente de trabalho, uma das formas que o gay afeminado é estigmatizado é por meio do deboche, pela ridicularização de seus gestos ou pela ironia, mesmo entre os próprios homossexuais. Tal fato não foi observado somente nos trechos destacados, mas também na observação de campo, durante a qual foi possível perceber que, ao falar dos gays afeminados, alguns entrevistados reproduziam seu comportamento de forma irônica. $\mathrm{O}$ deboche também ocorre na referência aos gays afeminados como "viado", "bicha louca" e "mocinha". O uso do deboche ou de termos depreciativos para designar os gays afeminados remetem ao estigma corporal, conforme definido por Goffman (1978). Nesse sentido, não se pode pensar o estigma corporal atrelado somente à deformidade física, conforme Goffman (1978) aponta, mas sim a tudo que é relacionado ao corpo.

Os entrevistados percebem ainda que o empregador não vê com bons olhos o sujeito gay afeminado, pondo em cheque a sua competência, conforme afirma o entrevistado Lucas: "Na visão geral, sobre o que eu vejo sobre a visão geral, mas o empregador encara, sim, como escândalo o gay afeminado, ele encara. Não acredita na competência" (Lucas). O entrevistado acredita que os gays são punidos pelas organizações ao longo do processo de recrutamento e seleção: "Eu já percebi sim. Mas não falam que é isso; falam que são outros motivos, falam que não tem perfil, não tem experiência na área" (Tiago).

Quando indagado sobre a existência de igualdade de oportunidades para gays heteronormativos e gays afeminados, o entrevistado Rodrigo relata que não há esta igualdade: "Olha, eu gostaria de acreditar que sim, mas eu acho que mesmo inconscientemente, as pessoas que avaliam os candidatos que estão concorrendo a uma vaga, vão considerar o comportamento de não "heteronormativo" uma qualidade ruim da pessoa, ou talvez menos 
boa, sabe". Tal relato reforça a ideia de que o gay com comportamento heteronormativo é bem visto, enquanto o afeminado não, e neste sentido ser afeminado pode ser associado à uma característica negativa.

Um dos entrevistados revelou que alguns gays afeminados preferem ter comportamentos heteronormativos no ambiente de trabalho para evitar o sofrimento:

\begin{abstract}
Ah, eu acho que já é coisa pessoal dele, eu acho que já parte muito do preconceito. Porque um gay em si, gay que eu digo não afeminado, ele não sofre tanto preconceito que um gay afeminado. Porque um gay afeminado é visto como mulher, ou melhor, como trans. Então eu acho que ali dentro ele se assume gay, por causa do padrão da guerra. Mas fora dali ele não é gay, ele é um gay afeminado. Porque ele não vai ter tanto preconceito fora do que lá dentro, lá dentro tem muito preconceito (Antônio).
\end{abstract}

Interessante notar, nesse relato, que a associação com o preconceito, na visão do entrevistado, se dá em função do gay afeminado "ser visto como mulher", levando à interpretação de que o preconceito se refere não apenas aos homossexuais, mas principalmente àqueles que se assemelham às mulheres. Nessa perspectiva, é o fato de "parecer mulher" que os incapacitaria para o trabalho nas organizações. Outro relato no ambiente organizacional que exemplifica o preconceito sofrido por gays afeminados e, por extensão, pela semelhança com as mulheres, foi produzido pelo sujeito Lucas, quando questionado se a feminilidade era um empecilho para ele conseguir um emprego:

\begin{abstract}
Na verdade, como eu falei para você, não é bem uma exigência, se eu não tivesse me portado dessa maneira eu acredito que eu não estaria lá hoje, como várias outras pessoas bem afeminadas mesmo, tentaram entrar e não conseguiram, pessoas que foram bem na prova, isso nunca é aberto publicamente, mas no privativo é. Eu tinha ido bem na prova, se eu não tivesse tido essa, essa conscientização, da pessoa que me indicou (que não foi aceito por ser muito feminino), eu não estaria lá entendeu? (Lucas).
\end{abstract}

Por meio dos relatos anteriores percebe-se que o gay afeminado sofre "injustiças" no ambiente de trabalho e os entrevistados estão conscientes que são vítimas dessas práticas. A aparência masculina no gay mostra-se como um fator relevante para a contratação, e aqueles que possuem aparência "conservadora", ou seja, "heteronormativa" são "aceitos" e por essas características não seriam alvos de preconceito no trabalho.

Observa-se ainda que alguns sujeitos, em algum momento, se sentiram culpados por serem gays, ou então não acreditaram no potencial que possuíam para exercer algumas tarefas no trabalho, o que se identifica com o estigma de culpa. Porém, além do estigma de culpa, o estigma, de maneira geral, se faz presente no ambiente de trabalho, onde os gays afeminados são punidos de alguma forma pelas organizações. Observou-se que tal punição está atrelada a dois fatores: ser gay e ser feminino. $O$ fato de ser gay gera diversos tipos de punição no trabalho, implícitas ou explicitas, como deixar de promover um funcionário por conta de sua sexualidade, por exemplo, ou até mesmo não o contratar, como já relatado nas pesquisas de Irigaray e Freitas (2011). No que tange ao ser feminino, Butler (1993) afirma que é impossível dissociar a feminilidade das relações de disciplina, regulação e punição. 


\section{Considerações finais}

Como já evidenciado na seção "Introdução", este trabalho teve por objetivo compreender a estigmatização da feminilidade nas organizações, pela perspectiva do sujeito gay. A pergunta de pesquisa consistiu em: "Como é compreendida a estigmatização da feminilidade nas organizações, pela perspectiva do sujeito gay?"

A estigmatização da feminilidade nas organizações é compreendida pelos sujeitos gays por meio de características que têm por objetivo desqualificar e subjugar a feminilidade.

Constatou-se que os sujeitos compreendem o estigma da feminilidade a partir do momento em que o "ser feminino" é visto como inferior ao homem pela sociedade e pelas organizações, seja por meio do uso de palavras ou expressões pejorativas ou através de comportamentos irônicos e do deboche, quando se referem ao feminino, com o objetivo de manter o poder heteromasculino. Compreende-se, entretanto, que essas práticas constituem apenas a ponta do iceberg, e que muito há ainda por ser discutido sobre a temática proposta. Em vista disto, considera-se que o objetivo proposto no presente trabalho foi alcançado de forma parcial, uma vez que a discussão da relação entre estigma, gênero e feminilidade está longe de esgotar-se como tema de pesquisa. De forma bem resumida, é possível afirmar que as questões de gênero estão relacionadas às construções sociais que permeiam a existência de ambos os sexos. Por isso, todas as construções sociais sexistas foram dimensionadas, tomando a definição de sexo como justificativa. Tanto na sociedade quanto nas organizações, o sexismo tem sido estimulado, internalizado e exercido por homens gays bem como mulheres.

Contraditoriamente, uma vez que se trata de indivíduos que são alvo do preconceito sexista, as nuanças das falas dos homossexuais masculinos também revelaram a existência de preconceitos, mitos e a visão sexista dos papéis femininos. Além disso, ficou clara uma visão do "ser feminino" como alguém menos capaz, e a masculinidade como um atributo relacionado a alguém capaz. Isso demonstra que muitos gays ainda parecem acreditar no mito da fragilidade feminina, confirmando a aceitação e a reprodução, na sua prática, do processo de socialização diferenciada que recebem sujeitos femininos e masculinos. Por fim, ressalta-se que esse estudo é uma contribuição para a área de Estudos Organizacionais, pois trouxe um diálogo entre estigma e feminilidades, temas ainda pouco abordados quando considerada essa área de estudo. Nesse sentido, pode-se afirmar que a feminilidade é um dos artifícios utilizados na construção do gênero daqueles sujeitos que se consideram femininos, porém, no âmbito das organizações, essa construção nem sempre é bem-vista e aceita, considerando que a feminilidade é estigmatizada e posta como uma característica associada à incapacidade profissional.

Reconhecemos que o presente artigo possui algumas limitações, dentre elas está o recorte dos sujeitos selecionados para a pesquisa, que consistiram somente em homossexuais masculinos. Acreditamos que se fossem entrevistadas mulheres lésbicas, trans ou travestis outros achados poderiam emergir do campo. Outra limitação da pesquisa diz respeito ao 
recorte geográfico, restrito à cidade do Rio de Janeiro e uma cidade do interior do Estado. Possivelmente um recorte mais abrangente poderia indicar outras questões e perspectivas sobre a temática pesquisada, ou mesmo a convergência de visões sobre o tema.

Por meio desse estudo é possível que gestores de recursos humanos consigam rever práticas organizacionais e até mesmo propor códigos de conduta e ética que objetivem criar uma cultura organizacional aberta para a diversidade da força de trabalho, abrangendo a inclusão de mulheres, gays afeminados, transexuais etc. Teoricamente esse estudo possibilita compreender como a diversidade nas organizações, especificamente a feminilidade, é uma característica estigmatizada, em outras palavras, esse estudo possibilita que novas pesquisas sejam feitas partindo do pressuposto de que a feminilidade é fonte de estigma no contexto organizacional.

Para pesquisas futuras, indica-se estudos que tenham como objetivo desvelar as relações entre estigma, dominação masculina e feminilidade com outros sujeitos considerados femininos, como mulheres trans, mulheres cis, lésbicas etc. Deixamos como sugestão também estudos que objetivam relacionar em profundidade as organizações como agentes que tratam o feminino como uma característica relacionada à incapacidade profissional.

\section{Agradecimentos}

Agradecemos à CAPES pelo financiamento deste estudo. Agradecemos ao editor e aos pareceristas da RECADM pelas valiosas contribuições para o aprimoramento das ideias e discussões propostas no artigo.

\section{Referências}

Abramenko, L., Lovisi, G. M., Fonseca, D. L., \& Abelha, L. (2017). Atitudes dos trabalhadores de saúde mental em relação aos pacientes psiquiátricos em uma cidade do interior do Estado do Rio de Janeiro. Cadernos Saúde Coletiva, 25(2), 169-176.

Alvesson, M., \& Billing, Y. D. (2009). Understanding Gender and Organizations. London: Sage.

Andrade, Á. L. S., Cappelle, M.C.A, Brito, M.J, Paula Neto, A., \& Vilas Boas, L.H.B. (2002). Gênero nas organizações: um estudo no setor bancário. RAE- eletrônica, 1(1), 1-15.

Bardin, L. (2006). Análise de Conteúdo. Lisboa: Edições 70.

Barretto, R. S., \& Figueiredo, A. E. B. (2019) Estigma e violência na percepção dos profissionais de saúde mental de uma unidade psiquiátrica em hospital geral. Cadernos Saúde Coletiva, 27(2), 124-130.

Bauer, M. W., \& Aarts, B. (2015). A construção do corpus: um princípio para a coleta de dados qualitativos. In: M. W. Bauer, \& G. Gaskell (Orgs.). Pesquisa Qualitativa com Texto, Imagem e Som: Um Manual Prático (pp. 39-63). Rio de Janeiro: Vozes. 
Becker, G., \& Arnold, R. (1986). Stigma as a social and culture construct. The Dilemma of Difference. New York: Plenum.

Biernacki, P., \& Waldorf, D. (1981). Snowball Sampling: problems and techniques of Chain Referral Sampling. Sociological Methods \& Research, 1(2), 141-163.

Bourdieu, P. (2014). A Dominação Masculina. Rio de Janeiro: BestBolso.

Butler, J. (1993). Critically queer. GLQ - A Journal of Lesbian and Gay Studies, (1), 17-32.

Butler, J. (1988). Performative acts and gender constitution: an essay in phenomenology and feminist theory. Theatre Journal, 4O(4), 519-531.

Butler, J. (2015). Problemas de Gênero: Feminismo e Subversão da Identidade. Rio de Janeiro: Civilização Brasileira.

Cappelle, M. C. A., Lopes, M. C. O., \& Souza, N. L (2013). Mulheres, trabalho e administração. RIGS - Revista Interdisciplinar de Gestão Social, 2(2), 161-191.

Caproni Neto, H. L., \& Saraiva, L. A. S. (2018). Masculinidades, trabalho e reprodução de preconceitos: um estudo com trabalhadores gays, lésbicas e bissexuais. Revista de Administração IMED, 8(1), 191-215.

Casétte, J. B., Silva, L. C., Felício, E. E. A. A, Soares, L. A., Morais, R. A., Prado, T. S., \& Guimarães, D. A, (2016). HIV/AIDS among the elderly: stigmas in healthcare work and training. Revista Brasileira de Geriatria e Gerontologia, 19(5), 733-744.

Chizzotti, A. (2006). Pesquisa em ciências humanas e sociais. São Paulo: Cortez.

Collins, R. L., Eunice C. W., Joshua B. M., Audrey, B., Matthew, C., \& Elizabeth, R. (2019). Social marketing of mental health treatment: California's mental illness stigma reduction campaign. American Journal of Public Health, 109(2), 228-242.

Connel, R. (2003). Masculinidades. México: UNAN-PUEG.

Crocker, J., \& Major, B. (1989). Social stigma and self-esteem: the self-protective properties of stigma, Psychological Review, 96(4), 608-630.

Diniz, A. P. R., Carrieri, A. P., Gandra, G., \& Bicalho, R. A. (2013). Políticas de diversidade nas organizações: as relações de trabalho comentadas por trabalhadores homossexuais. Revista Economia \& Gestão, 13(31), 93-114.

Dresch, A., Lacerda, D.P. \& Antunes, J.A.V.J. (2015). Design Science Research: Método de Pesquisa para Avanço da Ciência e Tecnologia. Porto Alegre: Bookman.

Eccel, C. S., \& Grisci, C. L. I. (2011). Trabalho e gênero: a produção de masculinidades na perspectiva de homens e mulheres. Cadernos Ebape, 9(1), 57-78.

Ely, R. J., \& Meyerson, D. E. (2000). Theories of gender in organizations: a new approach to organizational analysis and change. In B. M. Staw, \& R. I. Sutton. (Orgs.) Research in Organizational Behavior: An Annual Series of Analytical Essays and Critical Reviews (pp. 109-146). Amsterdam: JAI Na Imprint of Elsevier Science.

Fontanella, B. J. B., Ricas, J., \& Turato, E. R. (2008). Amostragem por saturação em pesquisas qualitativas em saúde: contribuições teóricas. Cadernos de Saúde Pública,24(1), 17-27.

Garcia, A., \& Souza, E. M. (2010). Sexualidade etrabalho: estudo sobre a discriminação de homossexuais masculinos no setor bancário. Revista de Administração Pública, 44(6), 1353-1377. 
Gabriel, Y. (2008). Organizing Words: A Critical Thesaurus For Social And Organization Studies. Nova lorque: Oxford University Press Inc.

Godoi, C. K., \& Mattos, P. L. (2010). Entrevista qualitativa: instrumento de pesquisa e evento dialógico. In A. B. Silva, C. K. Godoi, \& R. Bandeira-De-Melo (Orgs.). Pesquisa Qualitativa Em Estudos Organizacionais: Paradigmas, Estratégias e Métodos. São Paulo: Editora Saraiva.

Goffman, E. (1978). Estigma: Notas Sobre a Manipulação da Identidade Deteriorada. Rio de Janeiro: Zahar Editores.

Goldwasser, M. J. (2012). "Cria fama e deita-te na cama": um estudo de estigmatização numa instituição total. In G. Velho (Org). Desvio e Divergência: Uma Crítica da Patologia Social. Rio de Janeiro: Zahar.

Gomes, R., \& Felix, B. (2019). O 'self' no armário: uma teoria fundamentada sobre o silêncio de gays e de lésbicas no ambiente de trabalho. Cadernos EBAPE.BR, 17(2), 375-388.

Hansen, L. L. (2002). Rethinking the industrial relations tradition from a gender perspective: an invitation to integration. Employee Relations, 24(2), 190-210.

Hassard, J., Hollyday, R., \& Willmot, H. (2000). Introduction: the body and organization. In J. Hassard, R. Hollyday, \& H. Willmot (Orgs.). Bodies And Organization (pp. 96125). London, Thousand Oaks, New Delhi: Sage Publications.

Hearn, J., \& Parkin, W. (2001). Gender, Sexuality and Violence in Organizations. London: SAGE Publication.

Irigaray, H. A. R., \& Freitas, M. E. (2011). Sexualidade e organizações: estudo sobre lésbicas no ambiente de trabalho. Organizações \& Sociedade, 18(59), 625-641.

Leão, A. L. M. S., \& Mello. S. C. B. (2011). Stigmata: como as marcas são usadas para marcar os consumidores. Cadernos Ebape, 9(1), 22-36.

Louro, G. L. (2013, novembro). Uma sequência de atos. Revista CULT, 185, pp. 31-34.

Louro, G. L. (1997). Gênero, sexualidade e educação: Uma perspectiva pós-estruturalista. Rio de Janeiro: Vozes.

Louro, G. L., Felipe, J., \& Goellner, S. V (2013). Corpo, Gênero e Sexualidade: Um Debate Contemporâneo na Educação. Petrópolis: Vozes.

Martin, L. G. (1986). Stigma: A Social Learning Perspective. The Dilemma of Difference. New York: Plenum.

Martin, J. (2011). Does Gender Inequality Ever Disappear? In E. L. Jeanes, D. Knights, \& P. Y. Martin. (Orgs.) Handbook of Gender, Work \& Organization (pp. 15-49). United Kingdom: Wiley.

Melo, M. C. O. L., Cappelle, M. C. A., Mageste, G. S., \& Brito, M. J. M. (2004). Representações femininas na mídia de negócios brasileira. Organizações \& Sociedade, 11(31), 103-118.

Melo, F. V. S., Farias, S. A, \& Kovacs, M. H. (2017). Estereótipos e estigmas de obesos em propagandas com apelos de humor. Organizações \& Sociedade, 24(81), 305-324.

Melo, Z.M. (2000). Estigma: espaço para exclusão social. Revista Symposium, 4, 18-22. 
Miguel, L. F., \& Biroli, F. (2014). Feminismo e Política. São Paulo: Boitempo.

Motta, F. C. P (1993) Controle social nas organizações. Revista de Administração de Empresas, São Paulo, 33(5), 68-87.

Molinier, P., \& Welzer-Lang, D. (2009). Feminilidade, masculinidade, virilidade. In H. Hirata, F. Laborie, H. Doari, \& D. Senatier. (Orgs). Dicionário Critico do feminismo. São Paulo: Editora UNESP.

Moura, R. G. (2019). A masculinidade tóxica e seus impactos na vida dos gays dentro das organizações. Revista Ciências do Trabalho, 2(13), 125-139.

Moura, R. G, Nascimento, R. P., \& Barros, D.F. (2017). O problema não é ser gay, é ser feminino: o gay afeminado nas organizações. Farol - Revista de Estudos Organizacionais e Sociedade, 4(11), 1478-1541.

Mozzato, A. R., \& Grzybovski, D. (2011, julho/agosto). Análise de conteúdo como técnica de análise de dados qualitativos no campo da administração: potencial e desafio. RAC - Revista de Administração Contemporânea, 5(4),731-747.

Muraro, R. M. (2007). História do masculino e do feminino. Rio de Janeiro: ZIT.

Parker, R. G., \& Angglenton, P. (2001). Estigma, discriminação e AIDS. Coleção Abia Cidadania e Direitos, 1, 9-17.

Saffioti, H. I. B. (1987). O poder do macho. São Paulo: Ed. Moderna.

Salih, S. (2015). Judith Butler e a Teoria Queer. Belo Horizonte: Autêntica Editora.

Santana, A. M. (2010, setembro). Relações de Gênero no Contexto do Curso de Serviço Social e a Predominância do Sexo Feminino na Profissão. Anais do Seminário "Gênero e Sexualidades em fluxo": interfaces cientificas, pesquisa e insubordinações, Aracajú, SE, Brasil, 20.

Santos, V. C. (2010). Indícios de sentidos e significados de feminilidade e de masculinidade em aulas de Educação Física. Motriz, 16(4), 841-852.

Santos, J. C. S., \& Antunes, E. D. D. (2011, maio). Relações de Gêneros e Liderança nas Organizações: Rumo a um Estilo Andrógino de Gestão. Anais do III EnGPR Encontro de Gestão de Pessoas e Relações de Trabalho, João Pessoa, PB, Brasil, 15.

Santos, M.P. (2015). A constituição e a administração da identidade de gênero homossexual masculino assumida no trabalho e a sua articulação com o consumo. Dissertação de Mestrado, Universidade do Grande Rio, Rio de Janeiro, RJ, Brasil.

Scott, J. G. (1999). Igualdade versus diferença: os usos da teoria pós-estruturalista. Debate Feminista, 13(3), 203-222.

Simões, J. A., \& Facchini, R. (2009). Na Trilha do Arco-Irris: Do Movimento Homossexual ao LGBT. São Paulo: Editora Fundação Perseu Abramo.

Silva, A., Bastos, G. M. F., Lima, T. C. B., Ferraz, S. F. S., \& Cabral, A. C. A. (2013). Sentido do trabalho e diversidade: um estudo com homossexuais masculinos. Revista ADM.MADE, 17(2), 85-105.

Siqueira, M., \& Fellows, A. Z. (2006). Diversidade e identidade gay nas organizações. GESTÃO.Org - Revista Eletrônica de Gestão Organizacional, 4(3), 69-81.

Sousa, S., António, M., Rosário C., \& Cristina Q. (2012). Stigmatizing attitudes in relatives of people with schizophrenia: a study using the Attribution Questionnaire AQ-27. Trends Psychiatry Psychother, 34(4), 186-197. 
Souza, E. M., Corvino, M. M. F., \& Lopes, B.C. (2013). Uma análise dos estudos sobre o feminino e as mulheres na área da administração: a produção científica brasileira entre 2000 a 2010. Organizações \& Sociedade, 20(67), 603-621.

Souza, E. M., Bianco, M. F., \& Junquilho, G. S. (2015). Contestações sobre o masculino no contexto do trabalho: estudo pós-modernista em mineradoras e siderurgias. RAC - Revista de Administração Contemporânea, 19(3), 269-287.

Pereira, S. J. N. (2009, novembro) Entre Dois Mundos: Um Estudo Etnográfico Sobre a Cultura de Consumo Gay do Rio de Janeiro. Anais do XXXIII Encontro da ANPAD, São Paulo, SP, Brasil, 20.

Pépece, O. M. C., \& Miranda, A. P. C. (2019). Pérolas, Thatcher, e processos de ressignificação de gênero. Revista ADM.MADE, 23(1), 57-69.

Teixeira, J. C., Perdigão, D. A., \& Carrieri, A. P. (2016). O discurso gerencialista e a construção de ideais estéticos femininos e masculinos. Farol - Revista de Estudos Organizacionais e Sociedade, 3(7), 366-417.

Veiga, M. R. M. (2012). Corpo e envelhecimento femininos: herança do patriarcado? Sociais e Humanas, 24(1), 18-30.

Villela, W. V., Monteiro, S. (2015). Gênero, estigma e saúde: reflexões a partir da prostituição, do aborto e do HIV/aids entre mulheres. Revista Epidemiologia e Serviços de Saúde, 24(3), 531-540.

Yujin, L., \& Soontae, A. (2018). Effects of attributions and social media exposure on obesity stigmaamong korean adolescents. Social Behavior \& Personality: An International Journal, 46(12), 2049-2062.

Wellman, J. D., Araiza, A. M., Solano, C., \& Berru, E. (2019). Sex differences in the relationships among weight stigma, depression, and binge eating. Appetite, 133(1),166-173.

Welzer-Lang, D. (2001). A construção do masculino: dominação das mulheres e homofobia. Revista Estudos Feministas, 9(2), 460-482. 